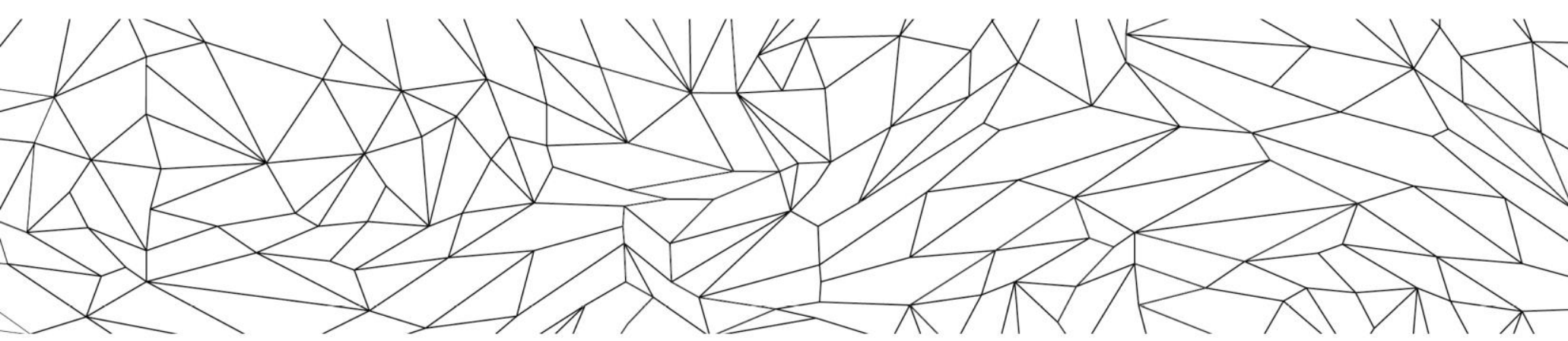

\title{
The Effects of Natural Disasters on Price Stability in the Euro Area
}

John Beirne, Yannis Dafermos, Alexander Kriwoluzky, Nuobu Renzhi, Ulrich Volz and Jana Wittich

Working paper

No. 244

November 2021 
The SOAS Department of Economics Working Paper Series is published electronically by SOAS University of London.

ISSN $1753-5816$

This and other papers can be downloaded free of charge from:

SOAS Department of Economics Working Paper Series at http://www.soas.ac.uk/economics/research/workingpapers/

Research Papers in Economics (RePEc) electronic library at https://ideas.repec.org/s/soa/wpaper.html

\section{Suggested citation}

Beirne, J., Dafermos, Y., Kriwoluzky, A. Renzhi, N., Volz, U., Wittich, J. (2021), "The effects of natural disasters on price stability in the euro area", SOAS Department of Economics Working Paper No. 244, London: SOAS University of London.

Department of Economics SOAS University of London Thornhaugh Street, Russell Square, London WC1H OXG, UK Phone: + $44(0) 2078984730$

Fax: 02078984759

E-mail:economics@soas.ac.uk http://www.soas.ac.uk/economics/

(c) Copyright is held by the author(s) of each working paper. 


\title{
The Effects of Natural Disasters on Price Stability in the Euro Area
}

\author{
John Beirne*, Yannis Dafermos \\ Renzhis, Ulrich Volz"II and Jana Wittich"l]
}

\begin{abstract}
This paper investigates the impact of natural disasters on price stability in the euro area. We estimate panel and country-specific structural vector autoregression (VAR) models by combining estimated damages of disaster events with monthly data for the Harmonised Index of Consumer Prices (HICP) for all euro area countries over the period 1996-2021. Besides estimating the effect on overall headline inflation, we examine effects on its 12 main sub-indices and further sub-categories of food price inflation. This allows us to disentangle differences in the direction and strength of price effects across consumption categories. Our results suggest significant positive effects of natural disasters on overall headline inflation, with diverging results at the sub-index level. Positive inflation effects are particularly pronounced for prices of food and beverages, while negative effects prevail for other sub-indices. Our country-specific results suggest heterogenous inflation effects of natural disasters across different countries. A key implication of our findings is that climate change is likely to make it increasingly difficult for the European Central bank to achieve its inflation target.
\end{abstract}

JEL codes: E31, E52, Q54

Keywords: Natural disasters, climate, inflation, monetary policy, European Central Bank

*Asian Development Bank Institute. Email: jbeirne@adbi.org

${ }^{\dagger}$ SOAS University of London. Email: yannis.dafermos@soas.ac.uk

¥German Institute for Economic Research (DIW Berlin). Email: AKriwoluzky@diw.de

${ }^{\S}$ Capital University of Economics and Business. Email: renzhinuobu@gmail.com

${ }^{\mathbb{I}}$ Corresponding author: SOAS University of London, Thornhaugh Street, Russell Square, London WC1H 0XG, UK. Email: uv1@soas.ac.uk

"German Institute for Economic Research (DIW Berlin). Email: JWittich@diw.de 


\section{Introduction}

"I want to explore every avenue available in order to combat climate change. This is something that I hold very strongly and I believe that, as we have this price stability mandate [...], climate change actually has an impact on price stability. If we fail to measure externalities, if we fail to anticipate drought, if we fail to anticipate variations of prices of food, of energy, of services, then we are not doing our job."

Christine Lagarde, Interview with the Financial Times, July 7, 2020.

The European Central Bank (ECB) has recently decided to incorporate climate change into its operations and decision making processes (ECB, 2021a, 2021b). Yet, so far little is known on whether climate change affects price stability in the euro area - the ECB's primary objective. On the one hand, climate change is associated with an increase in the frequency and severity of natural disasters (IPCC, 2021; Stott, 2016; Simola, 2020). Evidently, natural disasters can affect the economy by destroying infrastructure, houses and harvests as well as disrupting supply chains. On the other hand, to date, there is no empirical evidence that natural disasters influence the price level significantly in the euro area. This is an important knowledge gap: understanding the impact of natural disasters on inflation is essential for the design of monetary policy in the era of the climate crisis. In this paper, we aim to fill this gap.

Our analysis relies on a panel structural VAR approach. We use the Harmonised Index of Consumer Prices (HICP), which is the target variable of the ECB's primary objective of maintaining price stability. This allows our results to be of direct relevance to the ECB's monetary policy. We employ monthly data to capture the immediate price responses following natural disasters. To disentangle potentially contrasting price effects across product categories, that might offset each other at the aggregate level, we disaggregate the overall HICP inflation into its main 12 sub-indices. Our results suggest that natural disasters have a statistically significant effect on overall headline inflation, with diverging results at the sub-index level. Positive inflation effects are particularly pronounced for prices of food and beverages, while negative effects prevail for other sub-indices. The results also suggest heterogeneous effects of natural disasters across countries. 
The remainder of this paper is structured as follows. Section 2 briefly discusses the potential impacts of disasters on inflation and reviews the relevant empirical literature. Section 3 describes the data that are used throughout the analysis. The empirical methodology is outlined in Section 4. Section 5 presents the empirical results. Section 6 concludes.

\section{Background and literature review}

From a theoretical point of view, natural disasters can have both positive and negative effects on inflation. On the one hand, natural disasters might create positive inflationary pressures since they may destroy crops, buildings and infrastructure and thereby cause negative supply-side shocks (Batten et al., 2020; Simola, 2020). These shocks can increase the costs of domestic producers and can create spill-over effects to foreign importers. Furthermore, transportation costs might rise due to damaged infrastructure or the need to import the goods from abroad, again causing upward pressures on prices and creating spill-overs across countries (Klomp and Sseruyange, 2021). From the demandside, natural disasters often spur reconstruction efforts, which may cause a temporary local boom in the prices of reconstruction goods.

On the other hand, inflation can also go down in the aftermath of a natural disaster. For example, the destruction of houses and physical capital of firms can diminish wealth, leading to reduced consumption and firm investment. This holds true even if households and firms are insured against losses from disasters: first, the cost of insurance can prevent additional consumption and investment; second, if weather shocks occur more often and more strongly due to climate change, the insurance costs will likely increase. Moreover, higher loan defaults in the aftermath of a natural disaster can cause a decline in the credit provision by banks, reinforcing the decline in consumption and investment. Empirical research has shown, for example, that climate vulnerability influences the availability and cost of corporate capital (Kling et al., 2021).

With the coexistence of upward and downward pressures on prices, the exact inflation effects in the aftermath of natural disasters cannot be determined a priori. In addition, 
it might turn out that consumer prices of some goods fall, while prices of other items increase.

Although a wide range of macroeconomic models have explored the effects of climate change on the macroeconomy under different global warming scenarios (e.g. Dietz and Stern, 2015; Nordhaus, 2018; Dafermos et al., 2018; NGFS, 2021), the historical effects of climate change on inflation and other macroeconomic variables have so far received relatively little attention. This is partially explained by the fact that in the case of climate change the past cannot be a good guide for the future: the non-linearities associated with global warming imply that the climate-economy relationships might fundamentally change in the future, especially if atmospheric temperature passes specific thresholds. However, given that atmospheric temperature has substantially increased over the last decades, exploring how climate change has already affected the macroeconomic system can provide useful insights from a policy making perspective.

So far, the econometric literature on the macroeconomic effects of climate change has primarily focused on the impact of atmospheric temperature and disasters on economic growth and productivity (see Botzen et al. (2019) and Kalkhul and Wenz (2020) and the references therein). There are also several studies that have investigated the effects of disasters on trade. $]^{1}$ Less attention has been paid to the impact of temperature and natural disasters on other macroeconomic variables.

A few recent econometric studies have investigated the impact of natural disasters or temperature shocks on inflation. Parker (2018) has explored the effects of natural disasters on inflation in a panel of 212 countries over the period 1980-2012. He has found that while the impact of natural disasters on inflation in developed countries is negligible, natural disasters have persistent effects on inflation in developing countries. His results also suggest that there are differences in the inflation impact by type of disaster and inflation sub-index. Heinen et al. (2019) have documented a positive impact of hurricanes and floods on inflation using a sample of 15 Caribbean countries. In contrast, Cavallo et al. (2013) have found no significant effect on prices in the aftermath of the

\footnotetext{
${ }^{1}$ See, for example, Gassebner et al. (2010), Oh and Reuveny (2010), Felbermayr and Gröschl (2013), El Hadri et al. (2019), and Osberghaus (2019).
} 
2010 Chile and 2011 Japan earthquakes. Moreover, Doyle and Noy (2015) have found that prices declined following the Canterbury earthquake in 2010 due to the decline in aggregate demand.

A couple of studies have explored the inflationary effects of temperature shocks. Faccia et al. (2020) have analysed the impact of country-specific summer temperature anomalies on inflation for 34 advanced economies and 15 emerging and developing economies over the period 1980-2018. They have found that very hot summers have medium-run negative effects on inflation. Using a sample of both developed and developing countries, Mukherjee and Ouatarra (2021) have documented positive effects of temperature shocks on inflation, with these effects being persistent for developing countries.

To date, a detailed analysis of the effects of disasters on inflation in the euro zone is still lacking. Our paper aims to close this gap by econometrically estimating the effects of natural disasters on inflation in the euro area during the period 1996-2021.

\section{Data}

Our sample includes monthly observations from 1996:01 to 2021:03 for the 19 euro area countries. To measure monthly inflation rates, we use data on headline inflation and its sub-indices. ${ }^{2}$ Data are taken from Eurostat and capture the price changes of consumer goods and services acquired by euro area households. Unlike other consumer price data, they are based on harmonised statistical methods and thus allow for crosscountry comparisons. Data are available for overall headline inflation, as well as for its 12 main sub-indices and further sub-categories. This allows to disentangle differences in the direction and strength of price effects across consumption categories.

To capture the impact of natural disasters, we draw on the EM-DAT database from the Center for Research on the Epidemiology of Disasters (CRED) at the Université Catholique de Louvain. This extensive database comprises detailed data on natural disasters, such as storms, floods, droughts, heat and cold waves, earthquakes, and volcanic

\footnotetext{
${ }^{2}$ For details on the classification of the individual sub-indices, see: https://appsso. eurostat.ec.europa.eu/nui/show.do?dataset=prc_hicp_midx\&lang=en
} 
eruptions, which occurred worldwide since 1900 up to the present. ${ }^{3}$ It also contains information on the strength of the disaster, as well as on the number of people killed and affected, and the estimated monetary damage. The EM-DAT data are compiled from various sources, including UN agencies, non-governmental organisations, insurance companies, research institutes and press agencies.

We follow the literature on the macroeconomic effects of natural disasters (Noy, 2009; Noy and Nualsri, 2011; Parker, 2018 and Fratzscher et al., 2020) and use the reported estimated damage as our disaster variable. This measure captures the direct damage to crops, property and livestock, measured in US dollars and valued at the moment of the event. As the effects of the disasters on inflation depend on the size of the disaster and to standardise across countries, we follow Fratzscher et al. (2020) and divide the estimated damage by the level of monthly current-price GDP in the affected country, 12 months prior to the event. In consequence, our disaster variable captures the estimated monetary damage of the event in percent of GDP.

We add numerous control variables to our model to account for other driving forces of inflation rates. We extract monthly data on the gross domestic product (GDP, ratio to trend), industrial production (excluding construction) and the unemployment rate for all euro area countries as well as on the nominal exchange rate to US dollars from the OECD's Main Economic Indicators and Key Short-Term Economic Indicators databases. Data on industrial import prices are drawn from Eurostat, brent crude oil prices are extracted from the World Bank Commodity Price Data.

\footnotetext{
${ }^{3} \mathrm{We}$ are aware of the fact that earthquakes and volcanic eruptions are not directly related to climate change, but rather result from tectonic processes. However, recent research indicates that climate change may, in the very long run, contribute to an increase in these processes. This, in turn, may induce earthquakes and volcanic eruptions to increase (Masih, 2018; Carrivick et al., 2018). Moreover, excluding earthquakes and volcanic eruptions from the analysis does not significantly alter our results, as they make up only a minor share of the overall disasters included in our sample. This is why we include them in our analysis.
} 


\section{Empirical methodology}

A panel structural VAR (PSVAR) is used to examine the response of headline inflation and its sub-indices for a panel of 19 euro area countries to shocks imposed on our disaster variable. The analysis also controls for the domestic drivers of inflation outlined in Section 3. This approach enables a determination to be made of the dynamics and duration of the effect of disasters on inflation. The PSVAR can be denoted as follows in its general specification, with structural shocks identified by a recursive restriction:

$$
Y_{i, t}=A(L) Y_{i, t-1}+\alpha_{i}+\mu_{i, t}
$$

where $Y_{i, t}$ refers to a vector of our selected endogenous variables of country $i ; A(L)$ is a matrix of polynomials in the lag operator $L ; \alpha_{i}$ denotes country-specific fixed effects to account for unobserved time-invariant heterogeneity across countries; and $\mu_{i, t}$ is a vector of disturbances. Note that the exogenous nature of the disaster variable allows us to employ a recursive identification scheme.

Due to the autoregressive nature of the PSVAR, fixed effects are intrinsically correlated with the regressors. Hence, we use the forward orthogonal deviation procedure proposed by Arellano and Bover (1995) to eliminate fixed effects, such that the transformed variables are orthogonal to the lagged regressors. The PSVAR incorporates three lags, which is selected using the Akaike information criterion. Apart from the PSVAR model, we also estimate country-specific SVARs for the 4 largest euro area countries, namely France, Germany, Italy and Spain. The set-up is in line with equation (1), adjusted for the country-specific case. Following Christiano et al. (1999), the identification strategy is based on a block recursive restriction, which results in the following matrix $A$ to fit a just-identified model:

$$
A_{m, n}=\left(\begin{array}{cccc}
a_{1,1} & 0 & \cdots & 0 \\
a_{2,1} & a_{2,2} & \cdots & 0 \\
\vdots & \vdots & \ddots & \vdots \\
a_{m, 1} & a_{m, 2} & \cdots & a_{m, n}
\end{array}\right)
$$

The ordering of the variables imposed in the recursive form implies that the variables at 
the top (such as $a_{1,1}$ ) will not be affected by the contemporaneous shocks to the lower variables (such as $a_{m, 1}$ ) while the lower variables will be affected by the contemporaneous shocks to the upper variables. We then place our disaster variable at the top in the ordering, which implies that it will only be affected by a contemporaneous shock to itself. Following the disaster variable, we place industrial production, the unemployment rate, and the monthly changes in the US dollar nominal exchange rate, import prices and oil prices next in the ordering. This implies that these domestic factors will be affected by contemporaneous shocks to natural disasters and themselves, but not by contemporaneous shocks to inflation. Importantly, we place inflation last in the ordering, which is not only based on the assumption that natural disasters will affect inflation, but also on the consideration that domestic macroeconomic factors also matter for inflation.

\section{Results}

\subsection{Panel results}

Figure 1 shows the impulse responses of euro area headline and core inflation to natural disaster shocks, together with $95 \%$ confidence intervals generated by Monte-Carlo with 500 repetitions. The scale of the disaster shock is normalised as one percentage point of monthly GDP. We find that headline inflation in the euro area significantly increases by 0.1 percentage points right after the disasters take place. The magnitude of the effects declines over the subsequent 2 months, at which point the impulse response also become insignificant, before dissipating from about 6 months onwards. For euro area core inflation, a similar pattern to headline inflation emerges, albeit at somewhat lower magnitudes. Overall, however, while it appears that euro area inflation responds significantly and positively to disaster shocks during the first month, these effects are not very substantial in size. Moreover, the effects are not long-lasting, as expected and also reflecting the literature.

[Figure 1 about here]

Given that the average inflation responses may mask different or even opposing effects taking place on sub-components of inflation, across different euro area countries, 
or both, we also perform the impulse response analysis at a more disaggregated level. Figure 2 shows substantial heterogeneity in the impulse response functions. Indeed, the prices of food, clothing, housing, electricity, household equipment, health, education, restaurants, and miscellaneous goods significantly increase after the disasters take place. On the contrary, the prices of transport and communication decrease instantaneously following disasters. For other categories, we find no significant effects. In line with the results for headline and core euro area inflation, the responses of the subindices of inflation to disaster shocks generally become insignificant after 2 months, with the effects converging to zero from around 6 months onwards. Figure 3 zooms in on the sub-categories of food and beverage inflation. Increases in food inflation are significantly driven by the price of bread and cereals, meat, fish, milk and eggs, sugar, and food products n.e.c.. On the other hand, we only find ambiguous effects in other categories.

[Figures 2 and 3 about here]

Overall, the panel results indicate that natural disasters affect the euro area headline inflation, as well as some of its sub-indices. While upward pressures are particularly strong for food and beverages, downward pressures prevail in other categories. The coexistence of upward and downward pressures for different product groups reveals the importance of distinguishing between product categories, that might be obfuscated at the aggregate level.

\subsection{Country-specific results}

We now turn to discuss the results from a series of country-specific structural VAR models for 4 large euro area economies: France, Germany, Italy and Spain. These four countries have been selected because they are the largest economies in the euro area and thereby have a significant effect on the monetary policy decisions of the ECB. The country-specific analysis enables us to determine whether the results for euro area inflation are concealing heterogeneity at the country level.

For France (Figure 4), headline inflation increases instantaneously as the disaster shock 
takes place, although the impulse response is not statistically significant, before decreasing significantly at around four months after the shock. The pattern is similar for core inflation, with much lower magnitudes. In the case of Germany (Figure 5), headline inflation decreases significantly around 3 months after the disaster shock, with the effect disappearing and becoming insignificant from around 6 months onwards. On core inflation in Germany, no significant responses to disaster shocks are found. For Italy (Figure 6), headline inflation responds significantly downwards at around 2 months after the disaster shock. It then rebounds positively 4-5 months after the shock, with the magnitude dissipating gradually thereafter, converging to zero and not significant from 6 months onwards. A similar reaction can be found in the case of core inflation in Italy. In the case of Spain (Figure 7), the response of headline inflation is negative and significant to a disaster shock at the point of initial impact, before increasing at around 3 months. The impulse response is largely insignificant otherwise. As emerged for the other countries, the reaction of core inflation in Spain displays a very similar pattern to that of headline inflation, with some differences in magnitudes. Overall, it is clear that there are some opposing effects across the four largest euro area economies. While there are both upward and downward inflation responses to disaster shocks evident, the aggregated significant responses during the first 6 months after the shock, positive inflation responses in Italy and Spain outweigh negative inflation responses in France and Germany.

[Figures 4-7 about here]

We also examine sub-categories of inflation responses to disaster shocks at the national level in France, Germany, Italy and Spain (see Figures A1 to A8 in the Appendix). For France, positive and significant responses in food and beverages, as well as clothing categories, emerge after around 3 months (Figure A1). In Figure A2, the response of inflation in food and beverages in France are driven by positive impulse responses for bread and cereals, coffee and tea, and soft drinks. These positive responses, however, are largely outweighed by negative reactions in other sub-sectors, including transport, communication and recreation. In the case of Germany, it is striking that the response of food and beverages inflation is negative and significant at 3 and 4 months after the disaster shock (Figure A3). This is the opposite of dynamics for the euro area as a whole. 
Negative and significant responses in transport and communications inflation are also evident for Germany. The responses in inflation for fruit and vegetables appears to drive the overall decreases in food and beverages inflation for Germany (Figure A4). In Italy, food and beverages (and clothing) inflation response dynamics to a natural disaster shock are similar to those of Germany, with a negative and significant response after 2 months (Figure A5). Food prices responses are strongly driven by price behaviour in fruit and vegetables sub-categories, as well as coffee and tea (Figure A6). Negative inflation responses in Italy in food and beverages, however, appear to be outweighed by positive responses in transport, communication, and clothing sub-sectors. For Spain, we also find a negative and significant reaction of food and beverages inflation to a disaster shock after 3 months (Figure A7), with an important role for bread cereals and other food products (Figure A8). This negative effect in Italy is dominated by positive inflation responses in clothing and household equipment.

Overall, natural disaster shocks lead to different responses in inflation across different sub-indices of inflation across euro area economies, with negative and positive effects counteracting each other. This is not surprising: supply and demand factors, as well as the sectoral composition of the economy, have a strong bearing on the nature of these transmission channels and on which effect dominates.

\section{Conclusion}

This paper contributes to the literature about the macroeconomic effects of natural disasters. Using a structural VAR approach, we have estimated the effects of natural disasters on headline inflation and its main sub-indices in the euro area over the period 19962021. Our results suggest significantly positive effects of natural disasters on headline inflation, with diverging results at the sub-index level. Positive inflation effects are particularly pronounced for prices of food and beverages, while negative effects prevail for other sub-indices. In addition, country-specific impulse response functions aggregated over a 6-month horizon indicate that the mainly positive significant inflation responses in Italy and Spain outweigh the negative responses in Germany and France. Moreover, as expected, no long-lasting effects of natural disasters shocks on inflation are found, 
with impulse response converging to zero and becoming insignificant from around 6 months after the disaster shock.

Our empirical results have several implications for the ECB's monetary policy in the era of the climate crisis. First, as global warming accelerates, climate-induced inflationary pressures at the euro area are likely to increase. This will make it more challenging for the ECB to achieve its inflation target in the future. Second, the divergent inflation responses to natural disasters at the product level suggest heterogeneous inflation experiences among households: households whose consumption basket consists of products that are more likely to experience an increase in prices in the aftermath of natural disasters will be more adversely affected compared to households whose consumption is proportionately less reliant on such goods. This might call into question the rationale of targeting an aggregate index of inflation. Third, the heterogeneity of the inflation effects of natural disasters among countries will make it increasingly difficult for the ECB to align inflation rates across countries and satisfy the needs of all individual member countries. Finally, given these effects of climate change on the ability of the ECB to achieve its inflation target, the ECB needs to consider how it can use its monetary policy and prudential tools to contribute to the reduction of emissions $4_{4}^{4}$ Contributing to an alignment of financial markets with a net-zero pathway in order to prevent catastrophic climate change is the best way for the ECB to mitigate climate-induced disruptions to its ability to achieve price stability.

It is important to highlight that our analysis has only considered the physical impacts of climate change on inflation, not transition impacts. As part of its European Green Deal, the EU has committed to achieving climate neutrality by 2050 - a goal that has been made legally binding by the European Climate Law. Climate policies to achieve the decarbonisation of the EU economy, such as carbon pricing, are likely to affect inflation and complicate monetary policy making (McKibbin et al., 2021). Moreover, the transition to net-zero can be expected to cause large-scale structural changes in EU member countries (Semieniuk et al., 2021), which may impact on both short- and longrun inflation dynamics. Overall, it will be imperative for the ECB to carefully consider the impacts of climate change on price stability and do whatever it takes to support a

\footnotetext{
${ }^{4}$ For several proposals in this direction, see e.g. Dafermos et al. (2021) and Dikau et al. (2021)
} 
smooth transition of the EU to a climate-neutral economy. 


\section{References}

Arellano, M. and O. Bover (1995), "Another look at the instrumental variable estimation of error-components models", Journal of Econometrics, 68(1), 29-51.

Batten, S., R. Sowerbutts, and M. Tanaka (2020), "Climate change: Macroeconomic impact and implications for monetary policy", in: T. Walker, D. Gramlich, M. Bitar, and P. Fardnia (eds.), Ecological, Societal, and Technological Risks and the Financial Sector. New York et al.: Springer.

Botzen, W.J.W., O. Deschenes, and M. Sanders (2019), "The economic impacts of natural disasters: A review of models and empirical studies", Review of Environmental Economics and Policy, 13(2), 167-188.

Christiano, L.J., M. Eichenbaum, and C.L. Evans (1999), "Monetary policy shocks: What have we learned and to what end?", in: J.B. Taylor and M. Woodford (eds.), Handbook of Macroeconomics Vol. 1. Amsterdam: Elsevier, 65-148.

Carrivick, J., C. Connor, C. Cooper, M. Gloor, A. Hooper, I. Lawson, I. Savov, A. Schmidt, G. Swindles and E. Watson (2018), "Climatic control on Icelandic volcanic activity during the mid-Holocene", Geology, 46(1), 47-50.

Cavallo, E., S. Galiani, I. Noy, and J. Pantano (2013), "Catastrophic natural disasters and economic growth", The Review of Economics and Statistics, 95(5), 15491561.

Dafermos, Y., Nikolaidi, M., Galanis, G. (2018), ”Climate change, financial stability and monetary policy", Ecological Economics, 152, 219-234.

Dafermos, Y., A. Kriwoluzky, M. Vargas, U. Volz, and J. Wittich (2021), The price of hesitation: How the climate crisis threatens price stability and what the ECB must do about it. Hamburg, Berlin and London: Greenpeace Germany; German Institute for Economic Research; and SOAS, University of London.

Dietz and Stern (2015), "Endogenous growth, convexity of damage and climate risk: how Nordhaus' framework supports deep cuts in carbon emissions". The Economic Journal, 125(583), 574-620. 
Dikau, S., N. Robins, and U. Volz (2021), Climate-neutral central banking: How the European System of Central Banks can support the transition to net-zero. London: Grantham Research Institute on Climate Change and the Environment, London School of Economics and Political Science and Centre for Sustainable Finance, SOAS, University of London.

Doyle L., and I. Noy (2015), "The short-run nationwide macroeconomic effects of the Canterbury earthquakes”, New Zealand Economic Papers, 49(2), 143-156.

Driscoll, J.C., and A.C. Kraay (1998), "Consistent covariance matrix estimation with spatially dependent panel data", The Review of Economics and Statistics, 80(4), 549-560.

ECB (2021a), An overview of the ECB's monetary policy strategy. Frankfurt: European Central Bank.

ECB (2021b), "Detailed roadmap of climate change- related actions". Frankfurt: European Central Bank.

El Hadri, H., D. Mirza, and I. Rabaud (2019), ”Natural disasters and countries' exports: New insights from a new (and an old) database", The World Economy, 42(9), 2668-2683.

Faccia, D., Parker, M. and Stracca, L. (2020), "Too hot for stable prices? International evidence on climate change and inflation", mimeo, European Central Bank.

Felbermayr, G., and J. Gröschl (2014), "Naturally negative: The growth effects of natural disasters", Journal of Development Economics, 111, 92-106.

Fratzscher, M., C. Große-Steffen, and M. Rieth (2020), "Inflation targeting as a shock absorber", Journal of International Economics, 123(C), 103308.

Gassebner, M., A. Keck, and R. The (2010), "Shaken, not stirred: The impact of disasters on international trade", Review of International Economics, 18(2), 351-368.

Heinen, A., J. Khadan, and E. Strobl (2019), "The price impact of extreme weather in developing countries", The Economic Journal, 111(619), 1327-1342. 
IPCC (2012), Managing the Risks of Extreme Events and Disasters to Advance Climate Change Adaptation. A Special Report of Working Groups I and II of the Intergovernmental Panel on Climate Change [Field, C.B., V. Barros, T.F. Stocker,D. Qin, D.J. Dokken, K.L. Ebi, M.D. Mastrandrea, K.J. Mach, G.-K. Plattner, S.K. Allen, M. Tignor, and P.M. Midgley (eds.)], Cambridge: Cambridge University Press.

Kalkhul and Wenz (2020), "The impact of climate conditions on economic production. Evidence from a global panel of regions", Journal of Environmental Economics and Management, 103, 102360.

Kling, G., U. Volz, V. Murinde, and S. Ayas (2021), "The impact of climate vulnerability on firms' cost of capital and access to finance", World Development, 137, 105131.

Klomp, J., and J. Sseruyange (2021), "Earthquakes and economic outcomes: Does central bank independence matter?", Open Economies Review, 32, 335-359.

Masih, A. (2018), "An Enhanced Seismic Activity Observed Due To Climate Change: Preliminary Results from Alaska", IOP Conference Series: Earth and Environmental Science, 167, 012018.

McKibbin, W.J., A.C. Morris, P.J. Wilcoxen, and A.J. Panton (2021), "Climate change and monetary policy: Issues for policy design and modelling", Oxford Review of Economic Policy, 36(3), 579-603.

Mukherjee and Ouatarra (2021), "Climate and monetary policy: do temperature shocks lead to inflationary pressures?", Climatic Change, 167(3), 1-21.

Network for Greening the Financial System [NGFS] (2021), NGFS "Climate scenarios for central banks and financial supervisors", June

Nordhaus (2018), "Projections and uncertainties about climate change in an era of minimal climate policies". American Economic Journal: Economic Policy, 10(3), 333-60.

Noy, I. (2009), “The macroeconomic consequences of disasters", Journal of Development Economics, 88(2), 221-231. 
Noy, I., and A. Nualsri (2011), "Fiscal storms: Public spending and revenues in the aftermath of natural disasters", Environment and Development Economics, 16(1), 113-128.

Oh, C., and R. Reuveny (2010), "Climatic natural disasters, political risk, and international trade", Global Environmental Change, 20(2), 243-254.

Osberghaus, D. (2019), "The effects of natural disasters and weather variations on international trade and financial flows: A review of the empirical literature", Economics of Disasters and Climate Change, 3, 305-325.

Parker, M. (2018), "The impact of disasters on inflation", Economics of Disasters and Climate Change, 2, 21-48.

Semieniuk, G., E. Campiglio, J.-F. Mercure, U. Volz, and N. Edwards (2021), "Lowcarbon transition risks for finance", Wiley Interdisciplinary Reviews Climate Change, 12(1), e678.

Simola, H. (2020), "Climate change and the Russian economy”, BOFIT Policy Brief No. 11/2020. Helsinki: Bank of Finland Institute for Emerging Economies.

Stott, P. (2016), 'How climate change affects extreme weather events,' Science, 352(6293), $1517-1518$.

World Bank (2013), Building resilience: Integrating climate and disaster risk into development. Washington, DC: World Bank. 


\section{Figures}

Figure 1: Responses of headline and core inflation to disaster shocks
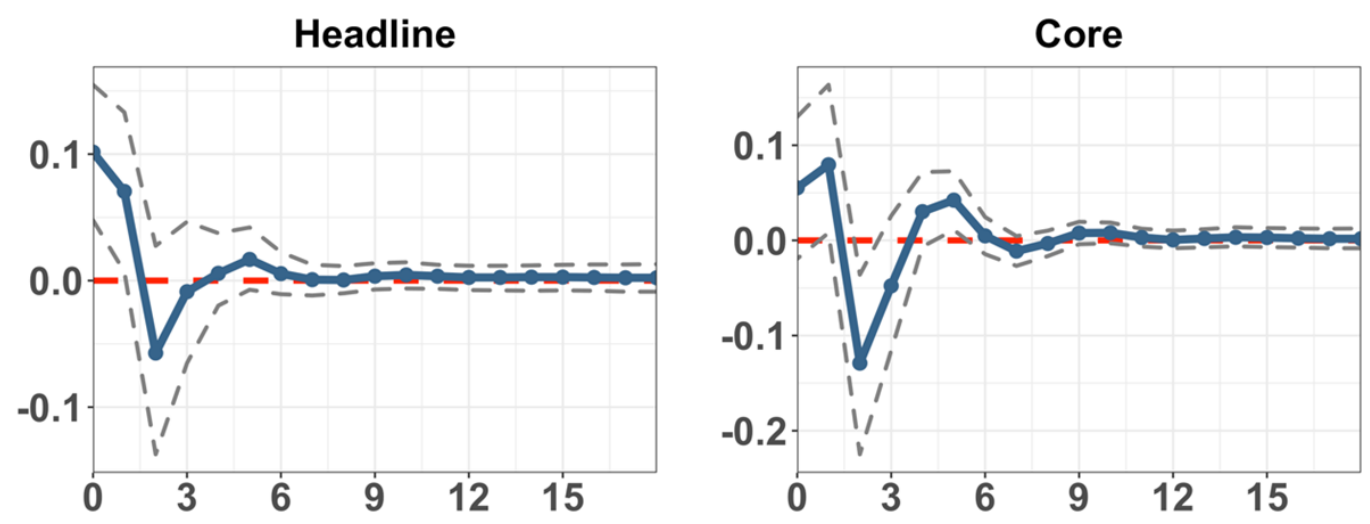

Note: Impulse responses with 95\% confidence bands in dashed lines are shown. The unit of disaster shock is one percentage point of monthly GDP, and the unit of the horizon axes refers to one month. 
Figure 2: Responses of inflation sub-indices to disaster shocks
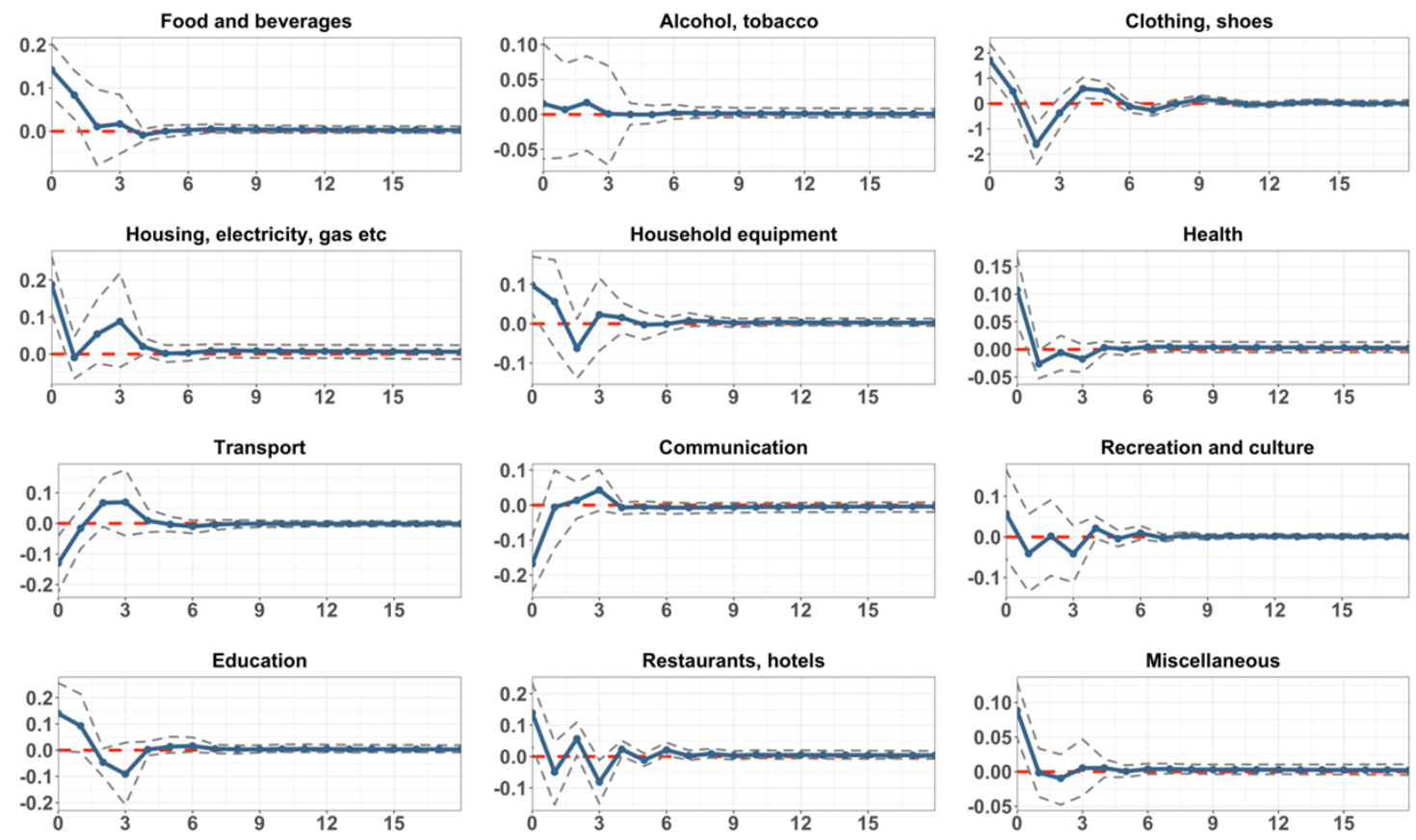

Note: Impulse responses with 95\% confidence bands in dashed lines are shown. The unit of disaster shock is one percentage point of monthly GDP, and the unit of the horizon axes refers to one month. 
Figure 3: Responses of food and beverages inflation to disaster shocks
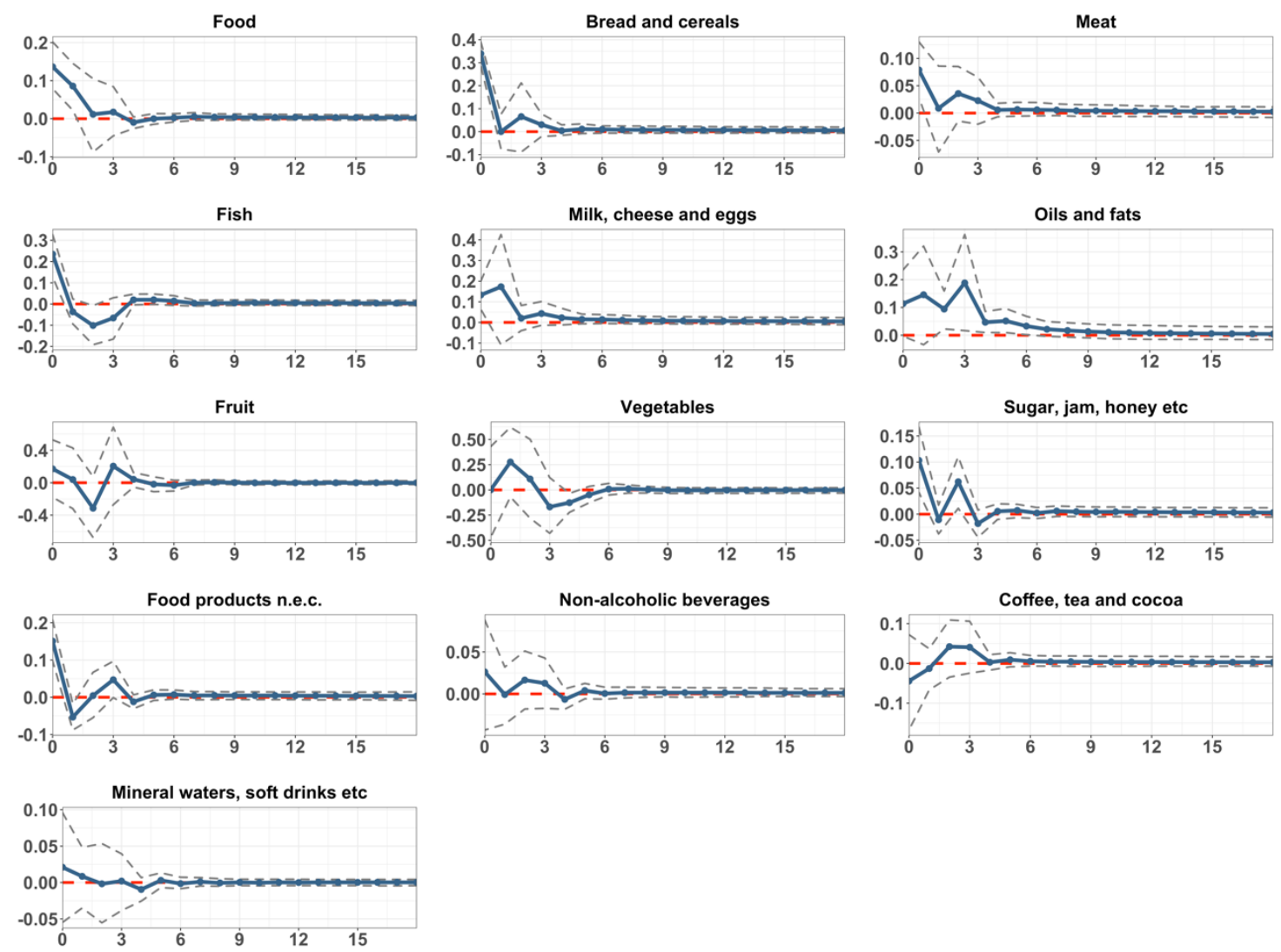

Note: Impulse responses with 95\% confidence bands in dashed lines are shown. The unit of disaster shock is one percentage point of monthly GDP, and the unit of the horizon axes refers to one month. 
Figure 4: Responses of headline and core inflation to disaster shocks: France
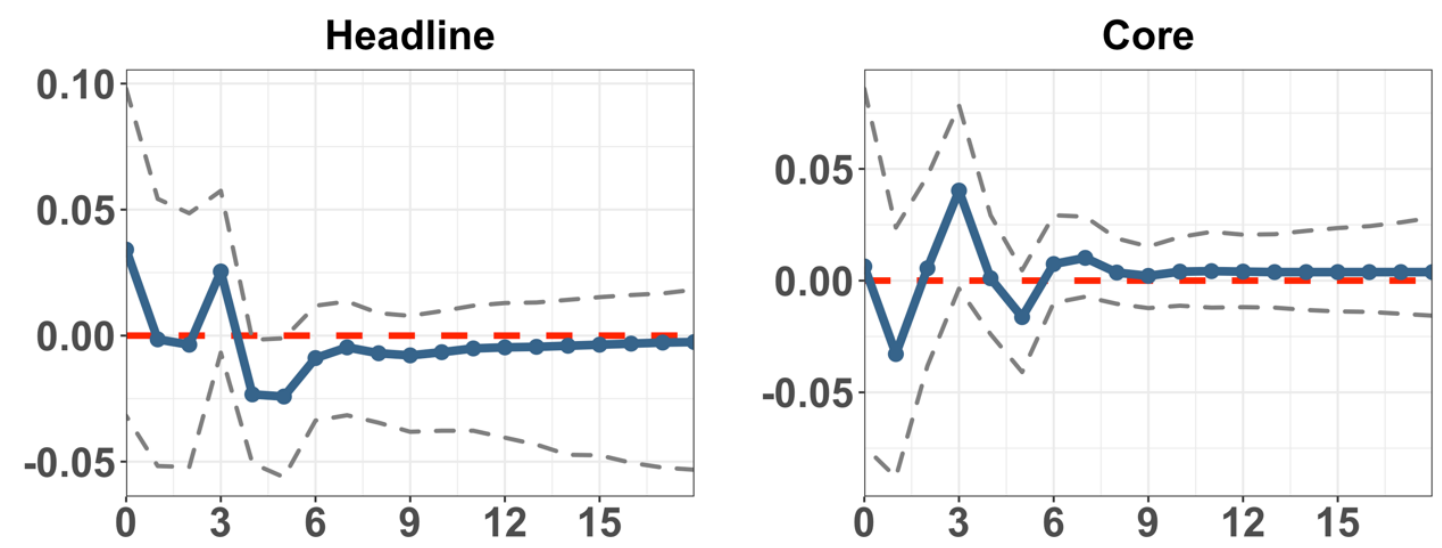

Note: Impulse responses with 95\% confidence bands in dashed lines are shown. The unit of disaster shock is one percentage point of monthly GDP, and the unit of the horizon axes refers to one month.

Figure 5: Responses of headline and core inflation to disaster shocks: Germany
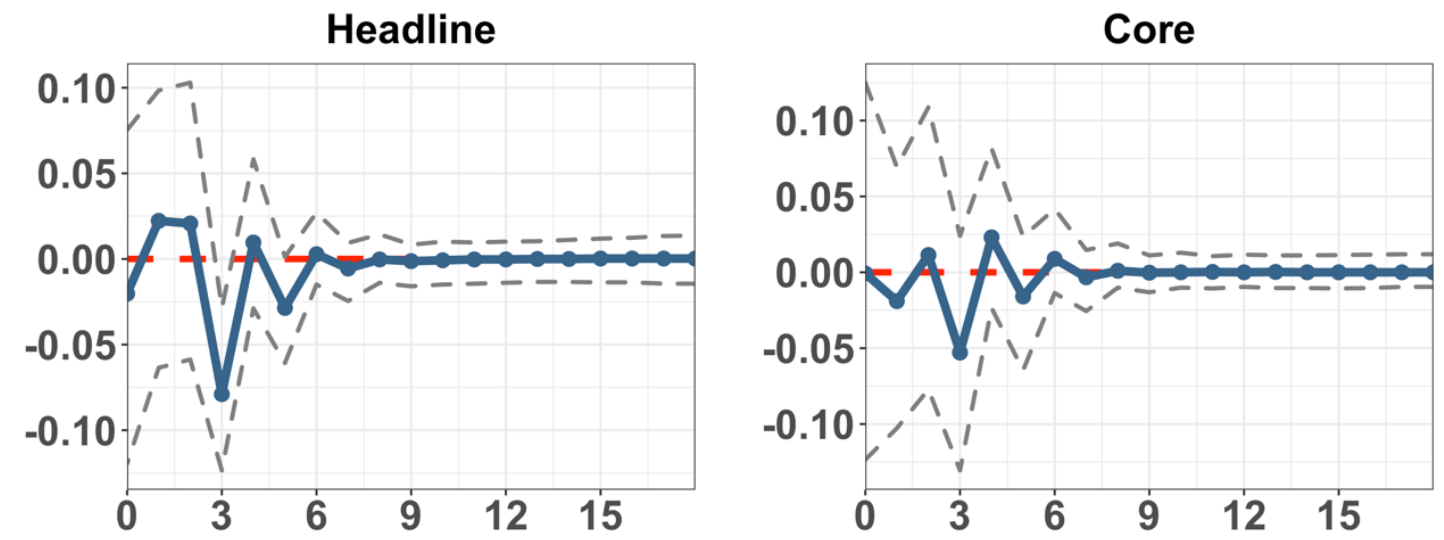

Note: Impulse responses with 95\% confidence bands in dashed lines are shown. The unit of disaster shock is one percentage point of monthly GDP, and the unit of the horizon axes refers to one month. 
Figure 6: Responses of headline and core inflation to disaster shocks: Italy

Headline

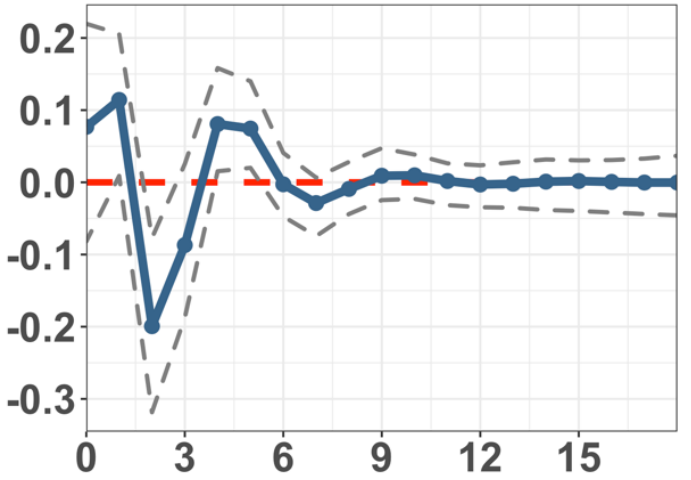

Core

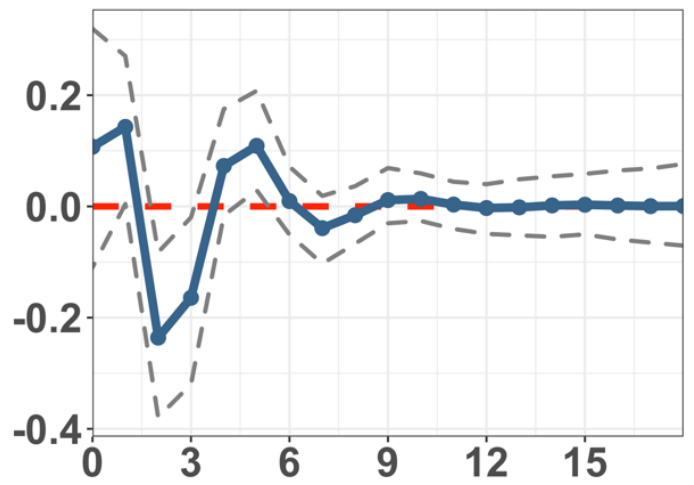

Note: Impulse responses with 95\% confidence bands in dashed lines are shown. The unit of disaster shock is one percentage point of monthly GDP, and the unit of the horizon axes refers to one month.

Figure 7: Responses of headline and core inflation to disaster shocks: Spain
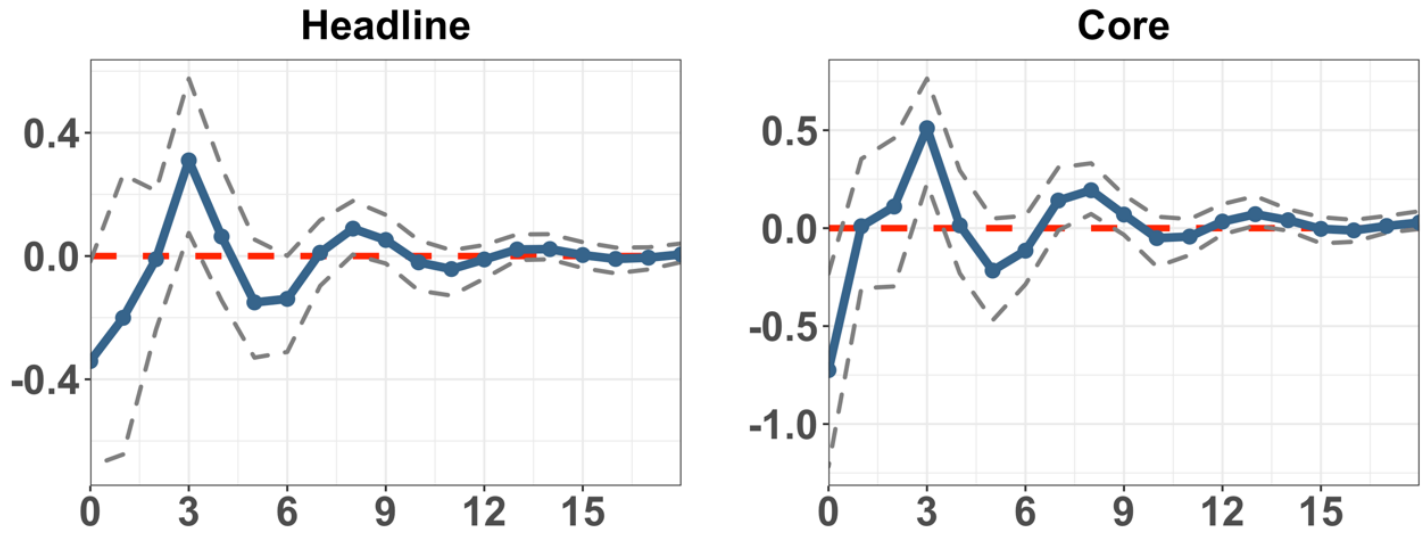

Note: Impulse responses with 95\% confidence bands in dashed lines are shown. The unit of disaster shock is one percentage point of monthly GDP, and the unit of the horizon axes refers to one month. 


\section{Appendix}

Figure A1: Responses of inflation sub-indices to disaster shocks: France
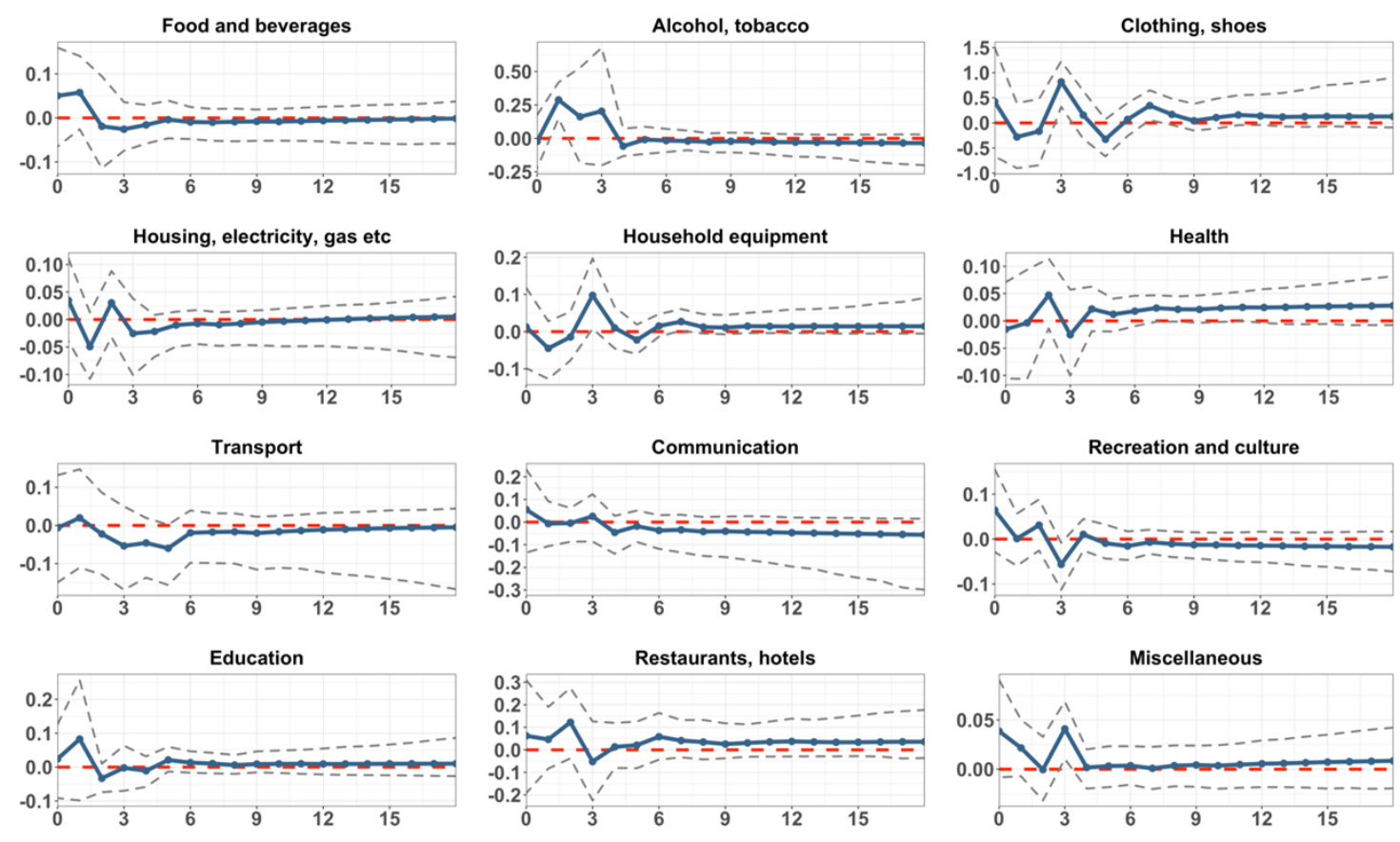

Note: Impulse responses with 95\% confidence bands in dashed lines are shown. The unit of disaster shock is one percentage point of monthly GDP, and the unit of the horizon axes refers to one month. 
Figure A2: Responses of food and beverage inflation to disaster shocks: France
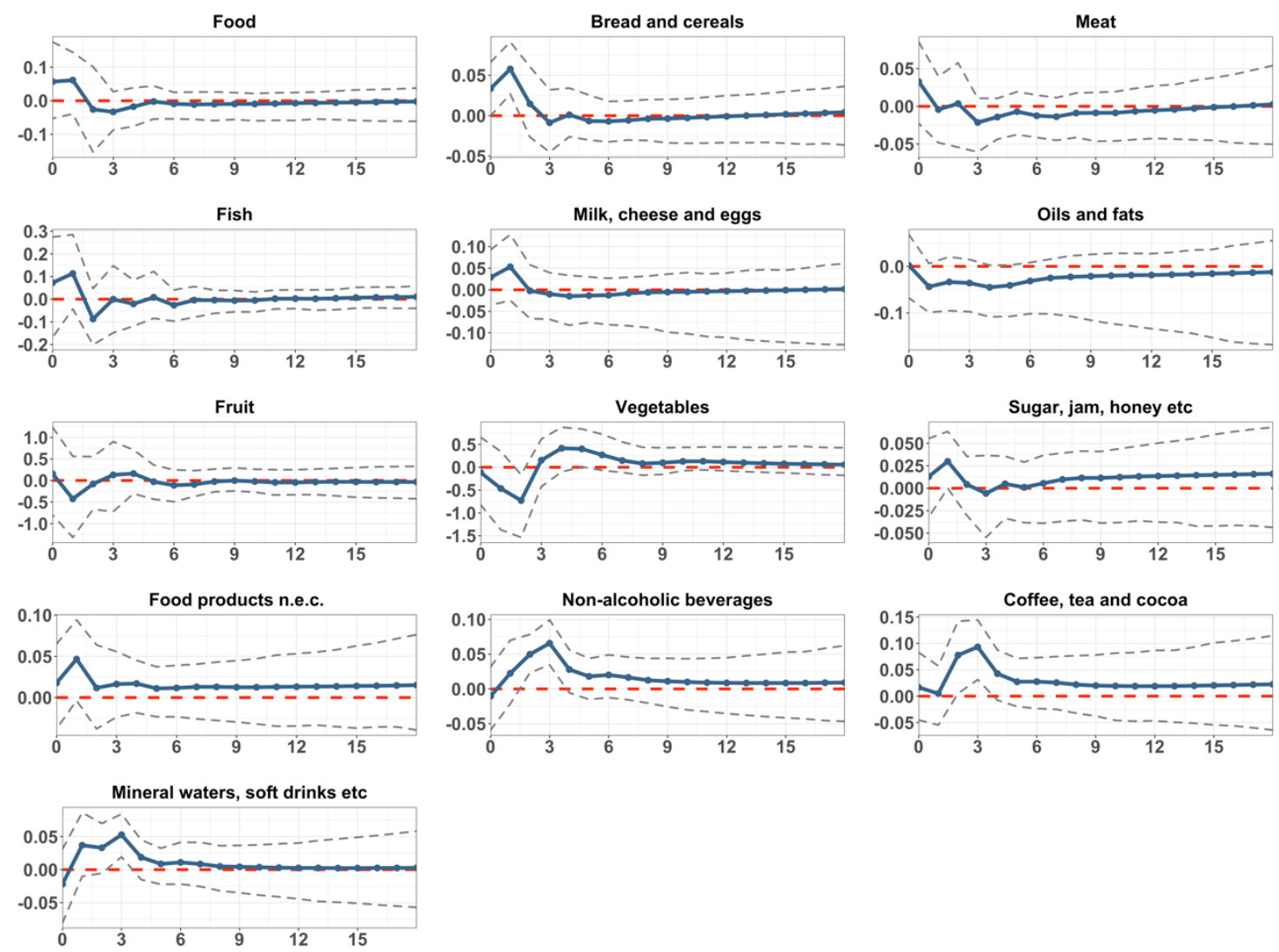

Note: Impulse responses with 95\% confidence bands in dashed lines are shown. The unit of disaster shock is one percentage point of monthly GDP, and the unit of the horizon axes refers to one month. 
Figure A3: Responses of inflation sub-indices to disaster shocks: Germany
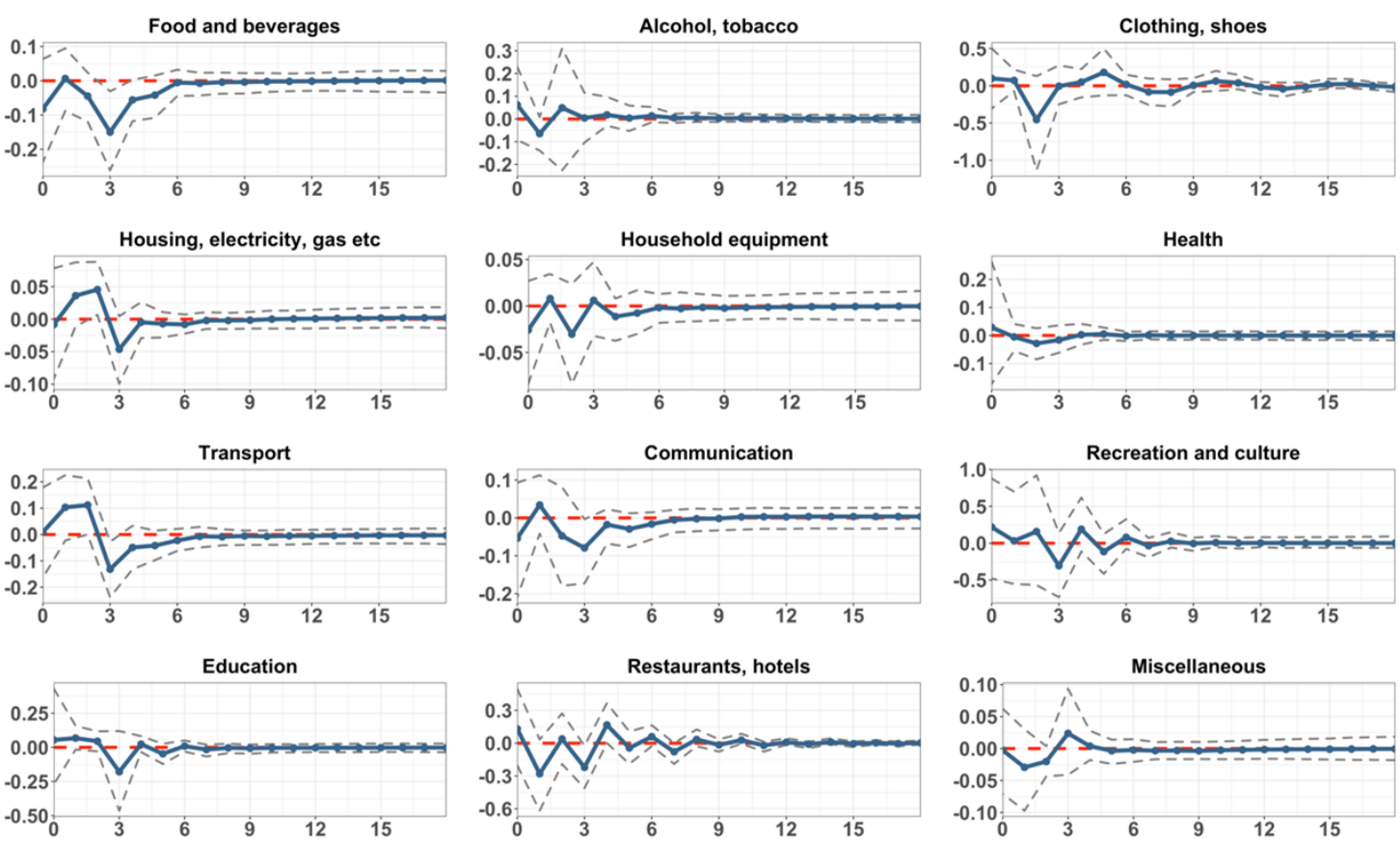

Note: Impulse responses with 95\% confidence bands in dashed lines are shown. The unit of disaster shock is one percentage point of monthly GDP, and the unit of the horizon axes refers to one month. 
Figure A4: Responses of food and beverage inflation to disaster shocks: Germany
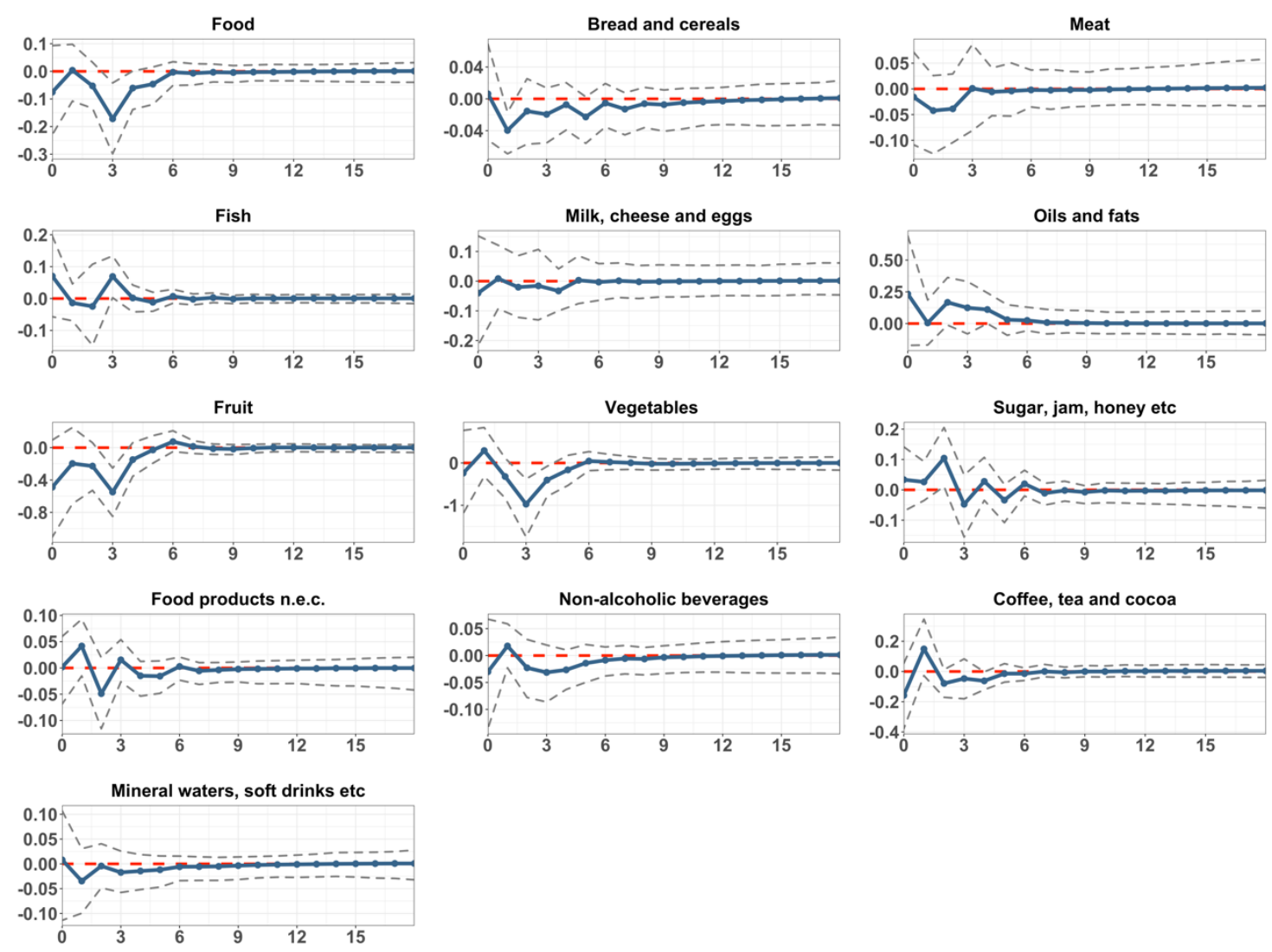

Note: Impulse responses with 95\% confidence bands in dashed lines are shown. The unit of disaster shock is one percentage point of monthly GDP, and the unit of the horizon axes refers to one month. 
Figure A5: Responses of inflation sub-indices to disaster shocks: Italy
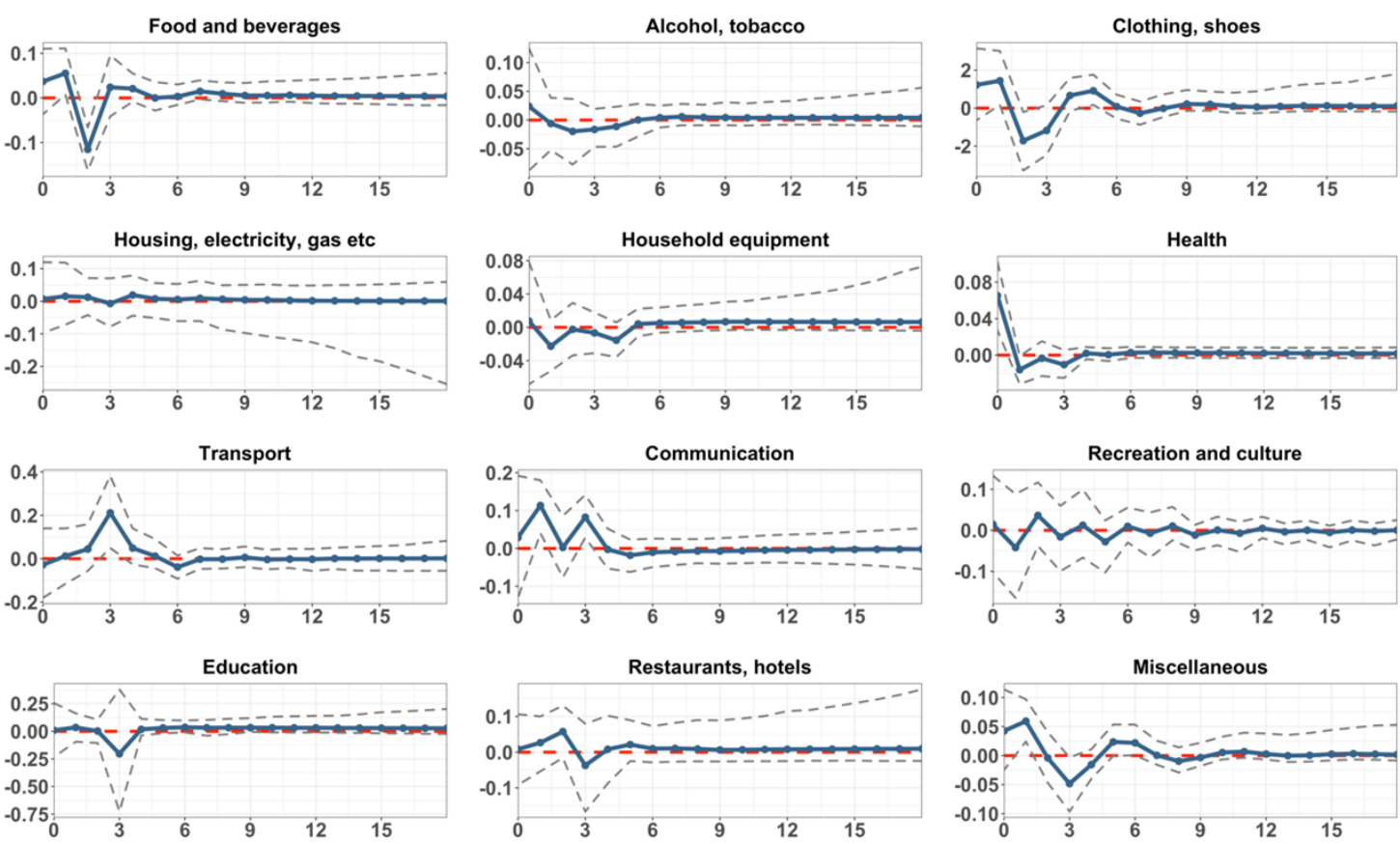

Note: Impulse responses with 95\% confidence bands in dashed lines are shown. The unit of disaster shock is one percentage point of monthly GDP, and the unit of the horizon axes refers to one month. 
Figure A6: Responses of food and beverage inflation to disaster shocks: Italy
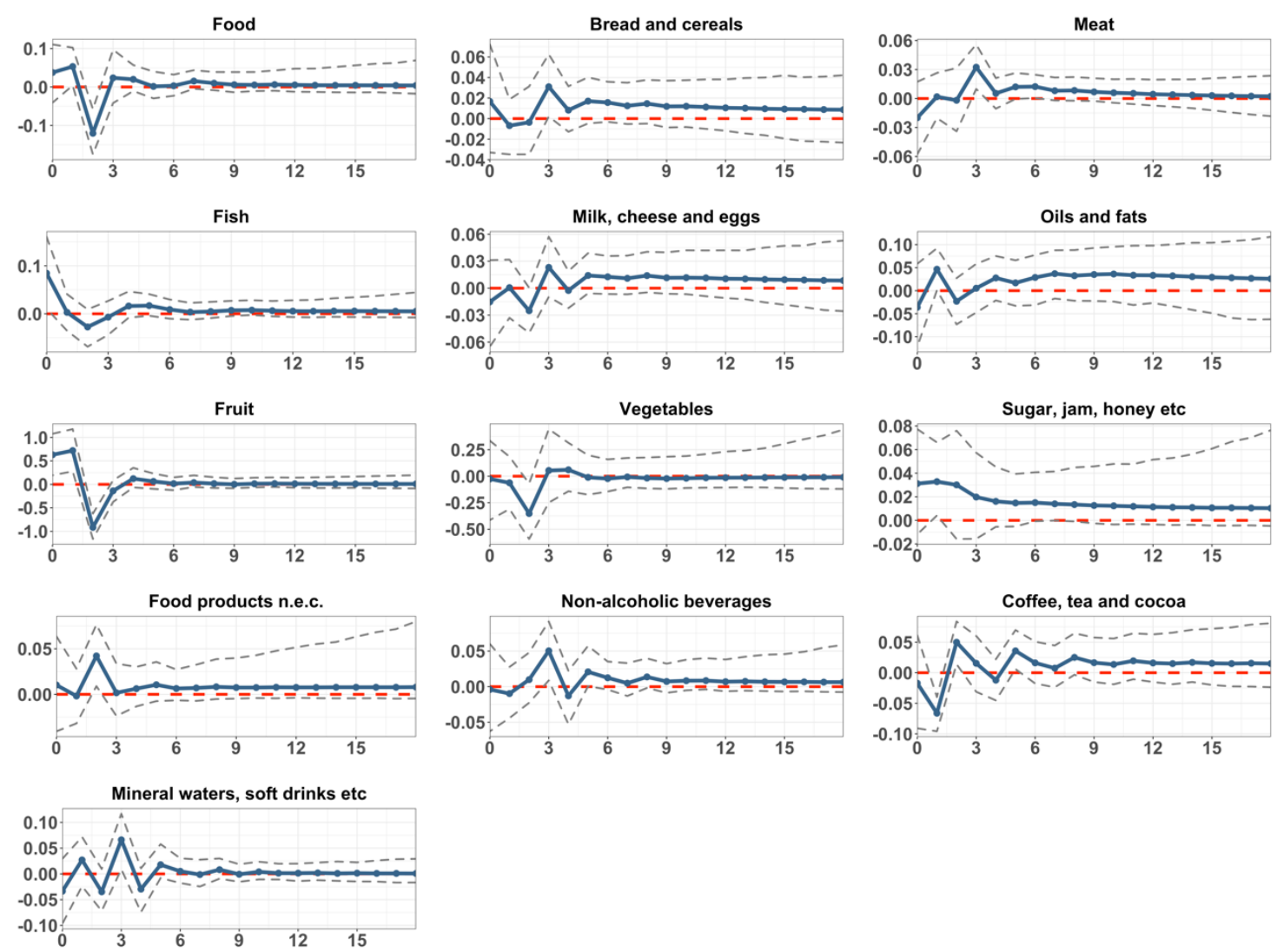

Note: Impulse responses with 95\% confidence bands in dashed lines are shown. The unit of disaster shock is one percentage point of monthly GDP, and the unit of the horizon axes refers to one month. 
Figure A7: Responses of inflation sub-indices to disaster shocks: Spain
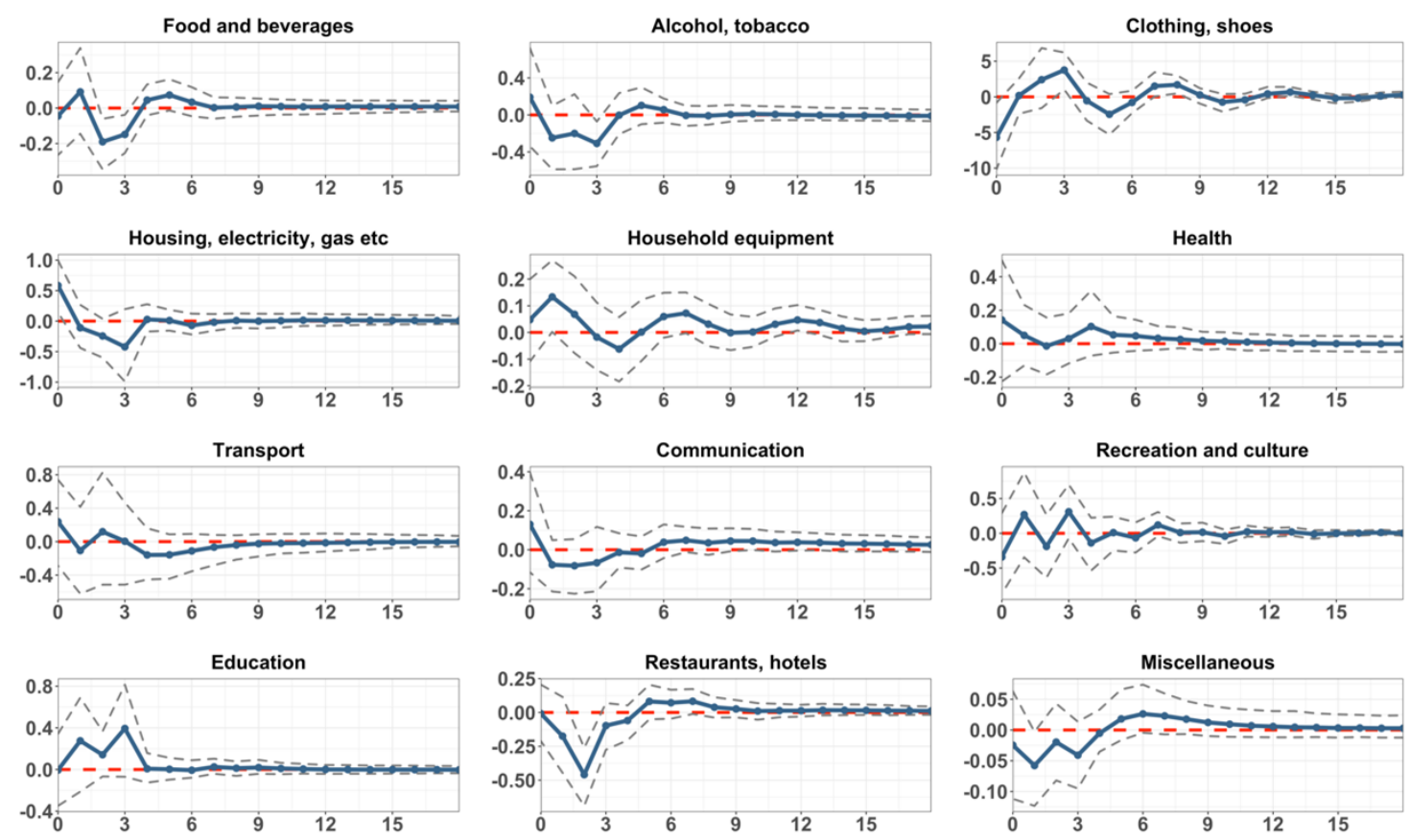

Note: Impulse responses with 95\% confidence bands in dashed lines are shown. The unit of disaster shock is one percentage point of monthly GDP, and the unit of the horizon axes refers to one month. 
Figure A8: Responses of food and beverage inflation to disaster shocks: Spain
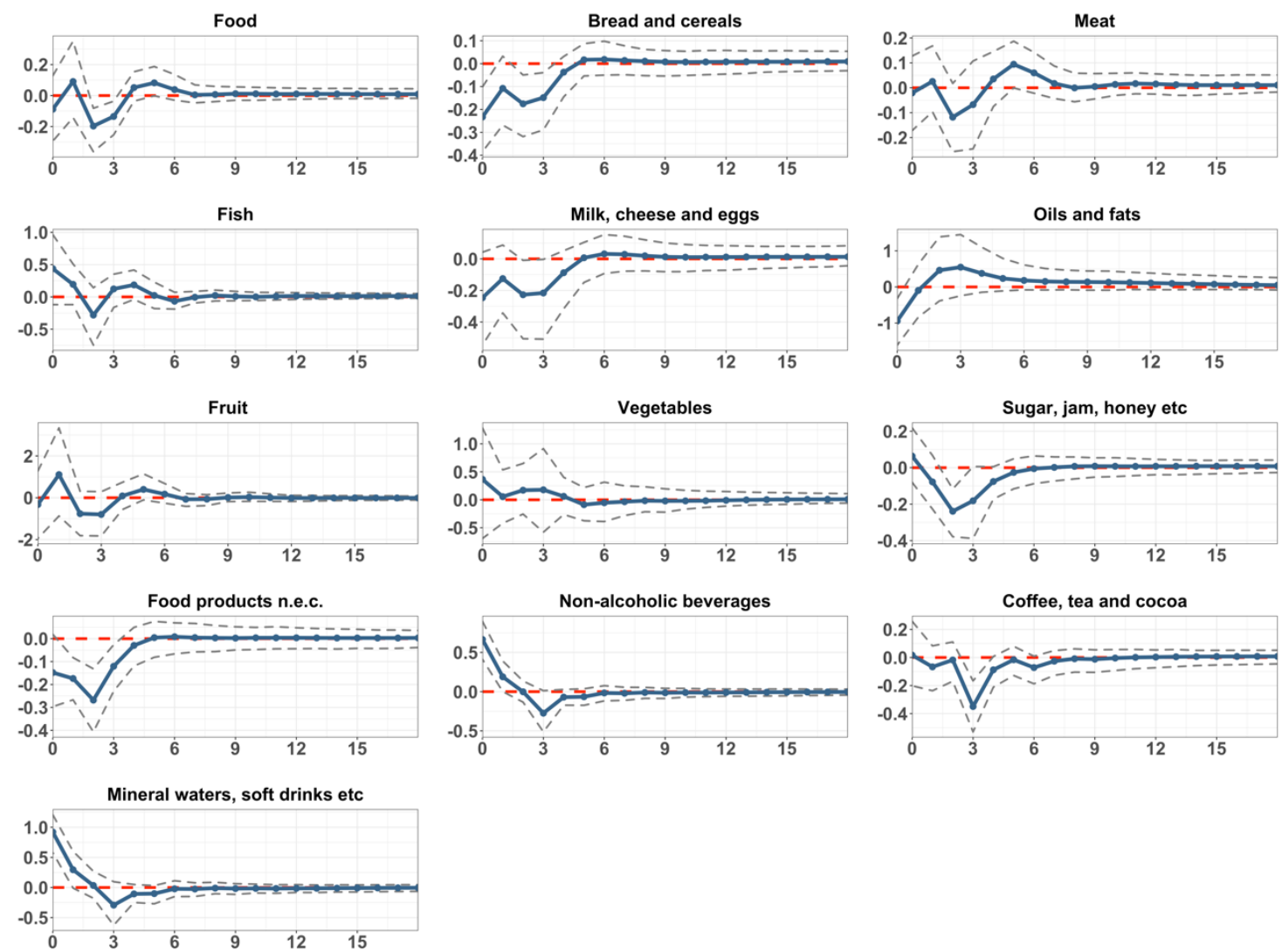

Note: Impulse responses with $95 \%$ confidence bands in dashed lines are shown. The unit of disaster shock is one percentage point of monthly GDP, and the unit of the horizon axes refers to one month. 